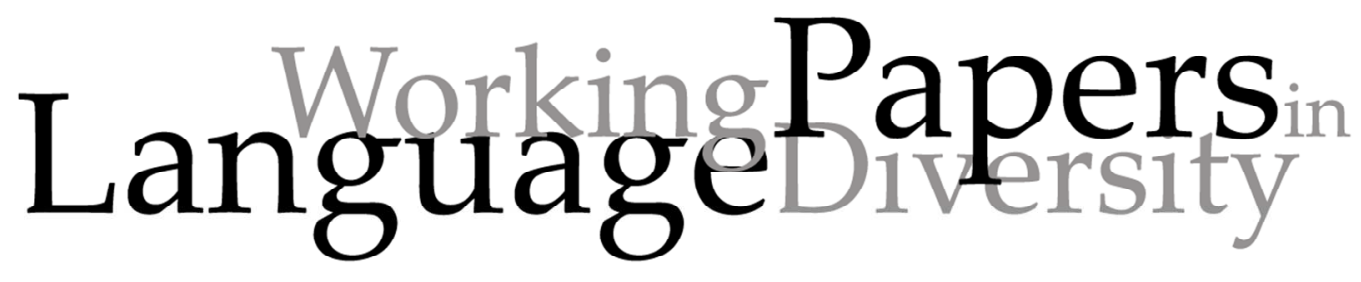

Paper 3.

\title{
Space, Scale and Accents: Constructing Migrant Identity in Beijing
}

\author{
Jie Kathy Dong \\ University of East London \\ Jan Blommaert \\ University of Jyväskylä and University of London
}

To appear in: Language and globalization: Scale, migration and communicative practice Collins, J., M. Baynham \& S. Slembrouck (eds.)

Contact: jie_dong77@yahoo.co.uk

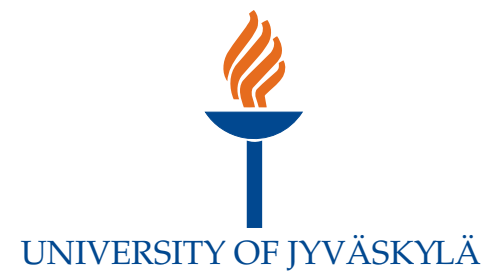




\begin{abstract}
This paper draws on the recently theorised notions of space and scale in sociolinguistics to investigate the complexity and micro-variation of the Chinese language in the context of mass internal migration, and the way in which sociolinguistic process shed light on the construction of migrant identities. In spite of the enormously rich diversity in Chinese languages, images of linguistic stability and homogeneity overlie the societal diversity that characterises every real social environment. The monoglot ideologies focused on Putonghua often present obstacles for migrant workers whose Putonghua proficiency is limited, and disqualifies their existing language resources and skills. Three vignettes will illustrate this. The first one demonstrates the presence and influence of Putonghua in an eastern coastal city through a story told by a migrant child; the second vignette reveals how a migrant worker's regional accent is misrecognised in the interactions with the locals; and the third vignette illustrates how a migrant worker is polyglot in one language and how this polyglot repertoire is organised indexically in relation to layered and stratified spaces. Therefore the monoglot ideologies often disqualify some people's linguistic resources; many migrant workers nevertheless develop a polyglot repertoire and navigate such obstacles.
\end{abstract}

Key words: China, space, scale, accent, identity, World-Systems Analysis (WSA), monoglot ideology, repertoire, globalisation, migration 


\section{Space, scale and accents: constructing migrant identity in Beijing}

\section{Introduction}

This paper will address the linguistic forms produced by Chinese internal migrants as well as the perceptions of such linguistic forms and identities derived from them, drawing on recent notions of space and scale in sociolinguistics. In doing so, it will question what Silverstein calls the "metaphors of linguistic hegemony": the language-ideological imagery of linguistic stability and homogeneity that overlies the overwhelming "evidence of societal plurilingualism" (Silverstein 1996: 284, also 1998). There is an old and widespread perception that China is a culturally, socially and sociolinguistically homogeneous region. The term 'Chinese' suggests homogeneity. This view is also shared by many linguists and sociolinguists, as studies on new varieties in which 'Chinese' is blended with English, such as Singlish (English used in Singapore), rarely question whether this 'Chinese' is the same as the one used in Beijing. The Chinese and the English blended in Singlish both carry heavy local accents, and thus the identifiably Singaporese character of Singlish is an effect of the accents rather than the languages. In other words: not just 'Chinese' and 'English' are blended in Singlish, but particular varieties of both languages. ${ }^{1}$

The complexity of the Chinese language and the sociolinguistic landscape it forms, thus, require a more nuanced approach focused on micro-variation - an approach that addresses what can be called a 'polyglot repertoire' within one language (Silverstein 1996). In such an approach, we assume that what is commonly perceived as a language - Chinese, for instance - is in fact an agglomerate of different varieties that operate and can be deployed as a repertoire. There are compelling reasons to develop such an approach, and perhaps the most compelling one is the increase in linguistic exchanges among various communities in China as a result of mass internal migration. The migration results in more complicated sociolinguistic environments, in which regional accents and dialects become salient markers of identity, and project prestige and opportunity, or stigma and inequality. ${ }^{2}$

\footnotetext{
1 This paper draws on fieldwork in Beijing between September and December 2006. Earlier versions of this paper were presented at the International Symposium on Second Language Teaching (Beijing November 2006) and the NORFACE Seminar Multilingualism as a Problematic Resource (Jyväskylä, March 2007). We are indebted to Pan Lin and April Huang as well as to the audiences on both occasions for feedback, comments and useful suggestions.

${ }^{2}$ Wong and Zhang (2000) offer evidence of similar micro-variation phenomena in the construction of gay and lesbian
} 
Rural-urban migration has taken place on a massive scale within China's borders in the last twenty years. It happens in the context of rapid economic and social changes both from inside China, and of China's integration in globalisation processes. A salient trend of this migration is people relocating from rural to urban areas; one can also observe such movements from smaller cities to bigger cities, and from western inland regions to eastern coastal regions. This phenomenal migration has attracted much attention from the field of education as well as from wider social research. Such research often focuses on the education provisions for migrant children (e.g. Han 2001; Lu and Zhang 2001; Woronov 2004), and the financial difficulties of accommodating migrant children in cities (Fan 2005). The linguistic forms produced by migrant workers, and the perceptions of such linguistic forms by migrants and urban communities, however, have been rarely explored. This paper aims to examine this complex of accents, space and scale in the theoretical framework of language ideologies.

Studies of language ideologies have fundamentally reshaped theories in sociolinguistics over the past decade, and have had an influence on applied linguistic issues such as literacy, normativity and standardisation (Silverstein 1996, 1998; Blommaert 2005a; De Fina, Schiffrin and Bamberg 2006). This paper situates itself in this emerging tradition, and adopts its basic conceptual as well as methodological instruments. It is an ethnographic study involving discourse analysis on news reporting, and observations as well as interviews on migrants' shifts in linguistic forms and styles produced in urban communities in Beijing, showing how they connect to and interact with one another in the particular space, and what indexical meanings the shifts of linguistic forms and styles project in the transitional social context in China.

In what follows, we shall introduce some key theoretical notions; secondly, we shall provide backgrounds on the internal migration in China, and thirdly, present an analysis of empirical data collected in late 2006 in Beijing as an illustration of the theoretical frame. In the final section, we will summarise the argument and offer suggestions for expanding and deepening this line of research.

identities in China. Gay and Lesbian communities appropriate Chinese political terminology such as 'tonghzhi' ("comrade") to identify their members, thus showing the creative ways in which people manipulate existing registers and repertoires to construct 'peripheral' identities. 


\section{Central concepts: space and scale}

This research draws on recent theories about sociolinguistic scales and spatial analysis (Blommaert 2005a, 2006; Blommaert, Collins and Slembrouck 2005a, 2005b), which are formed within a language ideologies framework (notably Silverstein 2004 and Blommaert 2005a). In this and related work, space is seen not just as a neutral background but as agentive in sociolinguistic processes. People who are highly linguistically competent may feel incapable of performing basic communicative tasks (such as asking for direction and catching a taxi) when they are in a foreign country, or indeed in a place where the linguistic conditions are noticeably different. We argued that such communicative problems occur not because these people lack the competence to communicate or interact per se, but because the space which organises patterns of language in particular ways has changed. Such a change of space results in a shift in the connection between one's linguistic repertoire and the linguistic competence required in that space, and therefore incapacitates him or her (Blommaert et al. 2005a).

Space, therefore, is not neutral. People speak in and from a space that projects particular value, social order, authority and affective attributes (Scollon and Scollon 2003; Blommaert 2005b). In such a space people take different positions and orient toward the topics and the interlocutors by systematically organising the patterns of speech, and therefore construct their identities in the performative process through social and linguistic interactions (Butler 1990; Goffman 1981; Blommaert, 2005a). Thus, space is not passive, but constitutive in shaping the way people connect to one another, in shifting linguistic patterns and styles towards particular topics, and hence in ascribing individual identities in interaction. People maintain their language competence, or even expand their linguistic repertoires and improve their communicative skills, but because they are 'out of place' and travel across spaces, they are incapacitated and experience the changes of value attached to certain linguistic resources and patterns.

Therefore "spaces are meaningful in relation to other spaces... [and they] are ordered and organised..., stratified and layered, with processes belonging to one scale entering processes at another scale" (Blommaert, 2005a:23). The notion of 'scale' introduces a vertical spatial metaphor: an image of a continuum on which spaces are hierarchically stratified and ordered 
from local to global with intermediary levels between the two poles (Blommaert 2006). The vertical move from one scale to another (e.g. from local to translocal, from momentary to timeless, from specific to general) involves and presupposes access to particular resources, and such access is often subject to inequality. Thus, a move across scales is also a power move. The notion of scale is developed as a critical extension of traditional concepts of 'trajectories', 'networks' and 'flows', in the way that scale is value-loaded and emphasises indexical meaning and semiotic resources, in an attempt to address sociolinguistic issues in the context of globalisation and diaspora (Blommaert et al. 2005a, 2005b).

Scale is a key concept in World-Systems Analysis, which describes the world as a system of structurally unequal parts organised as 'centres' (high level of capital accumulation, service economy, production of finished goods), 'semi-peripheries' and 'peripheries' (low level of capital accumulation, production of basic resources, dependent on the centres) (Wallerstein 1983, 2000, 2001). In the domain of sociolinguistics, the centre-periphery model is expressed, for example, through ‘central accents' such as British English and American English, and 'peripheral accents' such as Indian or Nigerian English (Blommaert et al. 2005a). Central accents project central identities, whereas peripheral accents project peripheral identities. Thus people consume enormous time and energy to acquire English with a British or American accent, but we see very few attempting to acquire Indian or Nigerian accent. Very similar processes can be observed in Chinese: Putonghua being a 'central accent' that is the medium of instruction in schools and that enables people's mobility across spaces, while provincial accents are primarily used at home and in informal occasions. ${ }^{3}$ In all of these instances, we see how particular varieties not only indicate regional origin but also produce indexical meanings of layered, stratified space - of centres and peripheries - and hence of identities that 'belong' to such spaces.

These scaling processes are valid at a world level, within a state (e.g. urban vs rural regions), within a city (e.g. business centre vs. disadvantaged areas), and neighbourhoods. Therefore, spaces are positioned against one another unequally. Some spaces are prestigious, while others project stigma. A move from rural to urban areas, for instance, is thus a move from the periphery to the centre, and central spaces may be difficult and costly to enter. Such

\footnotetext{
${ }^{3}$ Putonghua is the standardised variety based on the Mandarin Chinese spoken in Beijing and its nearby regions.
} 
movements are across spaces as well as across scales of social structure (Blommaert et al. 2005a). Theories of spatial analysis, identities construction, scaling processes and the centre-periphery models play key roles in understanding how migrants organise their linguistic repertoires, connect and interact with one another and with others in urban communities such as Beijing. Deploying concepts of space and scale allows us to study the phenomenal migration from a fresh perspective, as migration offers an enormously rich research potential of movements across spaces and scales, both in real terms and symbolically. The next section will briefly introduce the social contexts of the internal migration and of linguistic diversity across China.

\section{The China context}

\subsection{The internal migration}

The rural-urban migration started in the wake of dramatic economic reform and social changes in the 1980s. Since the launch of economic reform in 1978, China's GDP has been growing on an average of 9.4 percent per annum, with a 6-fold increase from 1984 to 2004 (Kuijs and Wang 2005). The average household income in 1985 was \$280, and it has risen sharply to $\$ 1,290$ in 2005 . In terms of global development, China contributed one-third of global economic growth in 2004. The UNDP Millennium Development Goal (MDG) report indicated that China's MDG in poverty reduction had been achieved by halving the proportion of the population living in poverty (estimated at 85 million in 1990) 13 years ahead of schedule (UNDP 2003). The reform transforms the urban manufacture and services industries, which attract millions of people from villages to cities.

Before the 1980s, population movement was tightly controlled by a system of "household registration' (hukou). The household registration system was put into place in 1958 and gradually became an instrument of controlling population movements during the three decades (1949-1979) of planned economy (Knight and Song 1999). It groups people into agricultural/rural or non-agricultural/urban hukou-holders at birth, and transgenerationally, as children depend on their parents' hukou status. Possessing a local hukou means one is entitled to local resources and social services.

While in the 1960s and 1970s, hukou functioned as a mechanism of tight control over 
population movement, it was gradually relaxed from the1980s onward in response to the rapid growth of manufacture and service sectors (Ma 1999). Migrants can move to and work in another locality without changing their household registration record. However, possessing a non-local hukou still means that one is not entitled to the welfare and social benefits from the local government of destination/host cities of migration.

The relaxation in hukou makes the mass population movements possible. The essential cause of the migration, however, lies in the very uneven levels of social and economic development among regions in China. The urban-rural income ratio was 3:1 in the late 1990s (Knight and Song 1999:29), and the GDP per capita was more than \$14,000 in Shanghai in 2002, which was 10 times than that of Guizhou, one of the poorest provinces in western China (UNDP 2003). The UNDP 2001 report indicated that the Gini coefficient ${ }^{4}$ was 40.3, which was similar to that of US (40.8) and UK (36.1). The rural-urban divide, rooted in the country's policies over a span of several decades, is ever more prominent as a result of economic reform, however.

Although the rural-urban divide is most salient, there are several dimensions of the uneven development: rural - urban, western inland (relatively poor regions) - eastern coastal (industrial, trading, and economically advanced regions), and the spatial continuum of cities, with the three centrally administered cities (Beijing, Tianjin, and Shanghai) at one extreme, small rural towns on the other extreme, and provincial capitals and medium-sized cities in between. Therefore the uneven development is not a simple divide between cities and villages, but a stratified and polycentric system in which villages and cities, inland and coastal regions, and hierarchically ranked cities all have the potential of becoming indexically organised spaces in a scaling process. All of these are at the infra-sate level, but bearing an influence of those at the supra-state level. The influx of migrant workers to the eastern coastal regions, such as Zhejiang province and Guangdong province, reflects such influences of China's increased participation in globalisation and the development of the industrial sector in that region (China's recent nickname 'the world factory' actually refers to that region).

The migrant population, according to the data of China $5^{\text {th }}$ Population Census in 2000,

\footnotetext{
${ }^{4}$ The Gini index measures inequality over the entire distribution of income or consumption. A value of 0 represents perfect equality, and a value of 100 perfect inequality. It is believed that there can be social tensions if the Gini coefficient exceeds 40.0 .
} 
reached 121 million in 2000, almost 10 percent of the nation's total population ${ }^{5}$ and this figure is expected to increase rapidly in the coming years (Fan 2004; Zou, Qu and Zhang 2005). In fact, the latest figures from a sampling survey conducted by the China National Statistics Bureau indicate that the migrant population had reached $147,350,000$ by $2005 .{ }^{6}$

Migrants used to be mainly young male farmers working in towns and cities for a few months during a year, probably in non-cultivating seasons. More recent investigations indicate that a high proportion tend to relocate as family units and stay longer in cities than before. They often do low-skilled jobs such as construction workers, waiters, cleaners, domestic workers, shoe mender, etc., the jobs that urban citizens tend to avoid. The huge migrant population and the extended period of urban experiences give rise to the intensive mix of people from various places of the state, carrying regional accents and dialects, and resulting in ever more complex linguistic and sociolinguistic environments.

\subsection{Linguistic diversity}

Linguistic differences are a salient mark of ethnic and regional group membership and place of origin in China which hosts 55 ethnic minorities, with Han Chinese being the majority. Many ethnic groups have their own languages, such as Mongolian and Tibetan. The languages of ethnic minorities have official status in their respective autonomous regions, and the Chinese policies encourage the use and development of minority languages in their regions (Zhou 2003). 'Chinese' is an umbrella term for the language spoken by the majority Han Chinese, which comprises many varieties. Linguists often categorise them into seven major dialects: Gan, Guan (Mandarin), Kejia (Hakka), Min (including the Hokkien and Taiwanese variants), Wu (including Shanghainese), Xiang and Yue (Cantonese) (Ramsey 1987:87). A recent trend is to recognise three more dialects: Hui, Jin and Ping dialects. These varieties, although may not mutually intelligible in some cases, are considered dialects (fangyan) because most forms of variation can be traced back to Middle Chinese (the language used during the Sui, Tang, and Song dynasties between 7th and 10th centuries AD), and some varieties in southern China maintain more features of Middle Chinese than the standard

\footnotetext{
${ }^{5}$ China $5^{\text {th }}$ Population Census showed that China's total population was 1.2 billion in 2000.

6 The latest figures are available at http://www.stats.gov.cn/tjgb/rkpcgb/qgrkpcgb/t20060316_402310923.htm, last viewed on 24 March 2006.
} 
variety of Mandarin Chinese (Ramsey 1987:111). Moreover, they share a largely common written system and a common literature. Fangyan, translated as 'dialect', means 'regional speech' literally, and as Ramsey suggests that, this term was used indiscriminately to refer to any speech that was different from Mandarin Chinese in the imperial periods, including the languages such as Korean, Japanese and Mongolian (1987:32).

In addition to the categorisation used by linguists, people customarily refer language varieties to particular places, often provinces, e.g. Dongbei dialect (the dialect of the north-east region), Henan dialect (the dialect of Henan province). Due to the mutual unintelligibility among China's languages and dialects, there has been always a need for a common language in the centralised state-systems that characterised China's history. The Mandarin Chinese based on the Beijing dialect was standardised over a few hundred years (Ramsey 1987). The standardisation began when the Ming Dynasty (1368-1644) relocated its capital from Nanjing to Beijing. The Qing Dynasty (1644-1912) commissioned Orthoepy Academies (Zhengyin Shuyuan) to standardise the Chinese pronunciation. This standard variety was named Guanhua (official language) in the first half of the twentieth century, and has been called Putonghua, ‘common speech', since 1955 (see Ramsey 1987 for a detailed account of the standardisation of Mandarin Chinese). The standard variety of Mandarin Chinese is the language of instruction in the education system of China, as well as the official language in the state's other institutions. It is reported that $53 \%$ of the Chinese people are able to communicate in Putonghua (China Daily 26/12/2004).

In the context of internal migration and linguistic micro-variations, the investigation of how migrants organise their linguistic forms, and how they communicate with one another and with local urban communities involves their sociolinguistic diversity, the space in which the interactions occur, the spaces across which he or she moves, and the scaling processes that indexically order and organise such spaces. Thus we ought to use a set of more sophisticated and layered theoretical instruments than the traditional ones in the field of sociolinguistic studies, in an attempt to look beyond language names and established categories such as 'language' and 'dialect', into the actual language varieties and their real social effects (cf. Hymes 1996). In the next section, three different vignettes will be presented that might illustrate such a more fine-grained sociolinguistic analysis. 


\section{Space, language and identity}

\subsection{Putonghua and monoglot ideologies}

As mentioned in the introduction, ideologies of homogeneity and uniformity overlay the societal diversity that characterises every real social environment. Often such ideologies monoglot ideologies (Silverstein 1996) - are dominant in the public debate on language and identity: they characterise policies as well as media and expert discourses (cf. Blommaert and Verschueren 1998). In China, such public discourses on homogeneity often revolve around the unquestioned status of Putonghua.

To understand the influence of Putonghua, let us examine a newspaper clipping taken from Ningbo Ri Bao (Ningbo Daily), the official newspaper of the Ningbo city. Ningbo is an emerging industrial and commercial centre in Zhejiang province of the eastern coastal region. This is a story told by a primary school student who comes from Sichuan province in the western inland region with her parents and attends a local Ningbo school (Ningbo Daily $31 / 10 / 2006)$.

"Last summer I arrived in this beautiful city with my parents. I was curious and excited by everything I saw in the streets: skyscrapers, broad streets, and flashing colourful lights... but I felt that all of these had nothing to do with me, because I was an outsider, a child of migrant works. After many twists and turns, my dad found a local school for me. I liked the school and my teacher, Miss Zhang, a young lady who spoke perfect Putonghua. She asked me to introduce myself in front of the class, but I couldn't - I couldn't speak Putonghua, how could I introduce myself? Miss Zhang was very kind and asked me to do so in my own dialect. I said 'good morning, I am a child from Sichuan...' (with marked Sichuan dialect) then was interrupted by a loud laughter from the class. I was so embarrassed that I just wanted to run away from the class. Miss Zhang helped me again 'what she used is standard Sichuan dialect!' After the class, Miss Zhang found me and told me that I should learn Putonghua 
otherwise I would encounter many difficulties in my life. Having her kind words in mind I was determined to study hard so that one day I would speak good Putonghua."

The story describes a child's migration experience: she travels from Sichuan province to Ningbo city of Zhejiang province, i.e. from the periphery to a regional centre. It is not clear whether she is from rural areas of Sichuan or not, but as discussed earlier, western inland regions (including Sichuan) are generally poorer and less developed than eastern coastal regions. The Sichuan accent is therefore an accent of the periphery - a marginal accent. And this marginal accent enters a space in which a 'central' accent dominates, i.e. Putonghua. There, it triggers laughter and shame. What is probably a marker of comfortable in-group identity in Sichuan has been 'downscaled' as a marker of rural, peripheral (i.e. stigmatised) identity in Zhejiang.

The accent is also one of the markers of the city's boundaries. The migrant child is noticeably attracted by the new space, but does not identify herself as a member of the city although her parents' work contributes to the rapid development of Ningbo. Here she encounters accent as the most salient marker of space boundaries - Ningbo is defined by the difference in linguistic variety - as well as a label of her migrant identity. Almost immediately after entering the school she notices that the teacher speaks "perfect Putonghua"; then she feels incapable of introducing herself because of not speaking Putonghua. The order of indexicality in which the child has entered has become clear now, and the child is 'language-less' 7 Her Sichuan accent clearly projects stigma when she introduces herself and she is embarrassed by her peer students' laughter. One trusts that the children do not laugh at her deliberately out of an unfriendly intention, and children need not disguise their feelings. However, the local children's natural reaction to her accent points to a social reality that linguistic forms are organised unequally in the particular space, and the Sichuan child's accent is neither usual nor high-ranked in this space: it is an 'abnormal' accent, bespeaking an 'abnormal' identity.

\footnotetext{
${ }^{7}$ This example is similar to the example of a Bulgarian immigrant woman who was labelled as "speaking no language" by local mainly Dutch-speaking researchers reported in Blommaert et al. 2005a. See also the example in 4.2.
} 
The teacher suggests her to learn Putonghua in order to integrate with the local urban communities and to have a better chance in life. Notice that differently from Beijing, Ningbo has its local dialect which belongs to $W u$ dialects, whereas Sichuan dialect is a variety of Mandarin and is much closer to Putonghua than $W u$ dialects (Ramsey 1987:89). The teacher does not require the migrant child to learn local Ningbo accent, but Putonghua, for the purposes of social integration and better opportunities in life. The connection between knowledge of Putonghua and opportunities in life ("otherwise I would encounter many difficulties in my life") is a matter of scale: Putonghua is the language of the government and for public life, it considerably enhances the social mobility across scales, from private to public and from low to high in society, of those who speak it, whereas it functions as a barrier for those who do not speak it. Here are three varieties of the Chinese language in action, which questions the language ideology of Chinese being linguistically homogenous. As observed in this example, Chinese is a 'polyglot repertoire' within one language: an agglomerate of different varieties that operate and can be deployed as a repertoire (Silverstein 1996).

\subsection{Being silenced by accent}

As mentioned above, Putonghua also incapacitates those who have limited competence in the standardised variety, diminishes mobility, and therefore projects stigmatised identities. Rather than an opportunity, it functions as a constraint for those who don't speak it. The effect is 'misrecognition' in the sense of Bourdieu (1990): despite the intrinsic value of people's symbolic resources, their value is not recognised in particular social contexts, and speakers are left without resources. A monoglot ideology such as the one described in 4.1 can function, thus, as a silencing instrument that misrecognises the resources that some people possess.

The example that follows is drawn from fieldwork observation in a public swimming pool in Liu Zhuang Street, ${ }^{8}$ a busy street on the fringe of Beijing. This is a newly developed urban area, highly mixed with local Beijing residents and migrant workers. The northern part of the street is dominated by local middle-class, whereas the southern part is a migrant community (see section 4.3 below). The swimming pool is run for the local residents, but

\footnotetext{
${ }^{8}$ Both the street name and the migrant's name are kept anonymous.
} 
because of the admission fee, it clearly targets the middle-class consumers living in the northern part of the street whereas excludes the southern migrant community. The cleaners of the swimming pool, note, are migrant workers. The episode runs as follows. While several young customers stood beside the pool chatting, a middle-aged female cleaner approached them and spoke to them while pointing agitatedly towards the floor. Because of her marked accent, none of the listeners understood what she had to say. From the tone, pitch, and emphases in her speech, it was clear that she complained about something the customers did. The listeners looked at each other puzzled, perhaps annoyed and offended, and then pretended not to hear anything (the loud music could be an excuse) and kept silent. After the cleaner had given up and left, the customers asked one another what the cleaner was talking about. After having established that no one had understood her, they giggled and changed the topic.

The cleaner is a fully competent speaker of her own dialect, and is most probably able to communicate in Putonghua at least on a basic level, because otherwise she would not have the chance to relocate to and work in the space - an urban community in Beijing. The space actively values local Beijing accent and/or the standardised Putonghua, whereas it devalues the cleaner's accent. This example echoes and expands what we saw in 4.1, and in both cases, people with marked regional accents are positioned in spaces that rank their accents low through a scaling process: their language variety only has limited, local validity; once it is 'exported' to middle-class, urban and central environments it loses function and value, it becomes misrecognised.

Misrecognition is a power tactic that forces the inferior party to adjust and adapt to the rules of the superior one. The superior, in turn, has no obligation to reciprocate this accommodating move. The customers do not understand what the cleaner wishes to address, but choose not to use any communicative technique to find out the meaning, and therefore the interaction terminates - or strictly speaking, little interaction takes place in the encounter. The termination of communication from the listeners' side may result from the difficulty of understanding the speaker, but this explanation is too superficial to address the listeners' silence and ignorance. A more plausible explanation would be the cleaner's accent, the inability of speaking in the valued variety of the space, and perhaps together with her appearance, project her identity as a migrant worker whose speech is not so important that the 
listeners have to find out the meaning. Large patterns of social structure - migration and the social positions it produces - seem to collapse here in patterns of interaction:

misunderstanding here is not a matter of just difference, but of difference within a system of inequality. The monoglot ideology described earlier appears to have produced forms of habitus among people that effectively makes the meaning of some people's speech senseless and meaningless.

\subsection{Navigating accents and space}

In the face of such obstacles, migrants have to navigate in order to make themselves understood as subjects. Often, such work involves a creative deployment of a wide range of varieties and discursive tactics. The interaction discussed here also took place in the same neighbourhood, Liu Zhuang Street. Ten years back it was a rural area, but with the rapid urban expansion, it has been turned into an urban community with many new residential developments which are particularly popular with young people (who mostly move from central Beijing to this peripheral area of the city, because of the reasonable property price and the efficient transportation system). The influx of new inhabitants creates business opportunities for migrants who relocate to Beijing as low-skilled and poorly paid workers. Due to the difference in economic patterns, the migration in Beijing is rather different from that in the eastern coastal regions: in the coastal regions migrant workers typically get jobs in the industrial and manufactory sectors, such as textile and shoe making, whereas they mainly work in the service sector e.g. garbage collector, cleaners, breakfast maker/seller in Beijing.

Beijing attracts millions of migrants. This street, Liu Zhuang Street, has an even higher concentration of migrant workers compared with central Beijing, because of its proximity to migrant communities' areas: south of the street, big and brand-new buildings gradually give ways to small, shabby, houses, with a more rural look and lower hygiene standards. The broad clean street turns into a narrow one covered with dust. In that part of the street, we see no more smartly dressed young people rushing to the tube station; instead, we will see old people dragging their legs and moving slowly and women washing clothes or feeding children. This is a mixed space filled with the rich and the poor; Liu Zhuang Street is a ready example of the centre-periphery model: the northern part (the part with many new developments and near to 
the tube station) is the centre, and southern part (migrant area) is the periphery, while the street itself is the periphery in relation to central Beijing.

In what follows we shall present and analyse a transcript of an audio-taped conversation between a migrant worker and Jie, the researcher, to illustrate how space shapes the way people connect and interact with one another and how spaces are ordered and organised in relation to one another through a centre-periphery model. We have this conversation in Beijing, and Jie (a native of Beijing) thus represent the 'centre', while the migrant represents the 'periphery'. In the transcript, the migrant whom we shall call Xiao Xu, sells breakfast (baozi, steamed dumplings) outside one of the newly developed property complexes in Liu Zhuang Street. The conversations are transcribed with Pinyin, the official spelling system of Mainland China since 1958, and then translated into English ( $\mathrm{X}=\mathrm{Xiao} \mathrm{Xu}, \mathrm{R}=$ researcher).

\section{Transcript.}

$\{\text { traffic noise, people talk unintelligibly }\}^{9}$

1 X. ni yao $*$ shen me [ $\operatorname{shr}^{2}$ mo] de (baozi)*? \{weak slow voice, noticeably trying to pronounce in local Beijing accent

R. ni zhe er dou you shen me de ya?

X. you...

$5 \quad \ldots$ conversations about the kinds of steamed dumplings he offers $\}$

R. nimen zhe er de shengyi tinghao de, zheme duo ren dou mai nimen de baozi.

X. $\{$ laughing voice $\}$ *jiushi* zaoshang hao, daole xiawu jiu mei ren chi baozi le $\{$ still making efforts to mimicking Beijing accent\}.

R. zaoshang shengyi hao jiu xingle. Neige xia de ni fang jin (dai er li) qu le ma?

$10 \mathbf{X}$. $\{$ nod with smile $\}$ nei tinghao de - women cong laojia dailai de.

\footnotetext{
${ }^{9}$ Transcription conventions:

',' (underline) stress

'=' interruption or next utterance following immediately

' \{\} ' transcriber's comment

'**' segment quieter than surrounding talk, or weaker than the rest of the sentence

' ( )' omitted part in the utterance

Letters in bold represent the shifts among the accents: Beijing accent - provincial accent - Putonghua - Beijing accent Putonghua.
} 
R. zhende?! Shi na er ya?

X. $\{$ proud, smile $\}$ women de xia doushi changjiang li de xia... tebie haochi $\left[\mathrm{t}^{\prime} \partial^{4} \mathrm{xo}^{3}\right.$

$\left.\mathrm{k}^{\prime} \mathrm{e}^{1}\right]$ \{his voice is noticeably higher and faster, and with clearer southern accent .

... conversations about how they brought the shrimps from that far away place

15 R. ni Putonghua shuo de ting hao de, zai xuexiao li xuede?

X. *hai xing ba*. You de (gu ke) ye buzhidao wo shuo shenme \{end with laughing voice, indicating this is a humble response $\}$

R. wo juede ni de Putonghua zhen tinghao de, wo tingde ting qingchu de ya.

X. en, zai xuexiao li xuede. Wo du dao gao zhong $\left[\mathrm{kau}^{1} \mathrm{chrog}^{1}\right]$ ne $\{$ switches from

20 noticeable southern accent to near-Putonghua\}.

*Ni jiu shi* $\left[\right.$ ni $^{3}$ chyiự shrị $\left.^{4}\right]$ Beijing ren? \{smile, and switch to certain characteristics of Beijing accent\}

R. ai. Wo jiushi zhe er de.

X. *jiushi zhe er de* $\left[\right.$ chyiư $^{4} \operatorname{shrị}^{4}$ chrer $^{4}$ de] $\{$ repeat in a low voice, still in a effort of producing Beijing accent $\}$

25 R. nimen zai xuexiao quan yong Putonghua?

X. women xue (Putonghua in school), ye shuo nei zhong fangyan.

R. na ni zenme lian de ya $\{$ smile $\}$ ?

X. wo... wo zai zhe er dai guo [tai ${ }^{1}$ kuo] $\{$ switch to his Beijing accent with a higher, prolonged and jolly voice, indicating he was pleased by my comment on his Putonghua, and was proud

30 that he was not a stranger to the city of Beijing

R. na ni dou ting de dong zhe er ren shuo hua ma?

X. ting de dong, jiu shi bie ren shuo fangyan $\left[\mathrm{fpy}^{1} \mathrm{ien}^{2}\right]$ wo ting bu dong \{ switches back to Putonghua\}.

R. = nashi. Bie ren shuo fangyan wo ye ting bu dong.

$35 \mathbf{X}$. = youde shuo fangyan, wo bantian buzhidao shenme ne $\{$ end with laughing voice, 
amused $\}$

R. jiu shi; erqie zhe di er ba, na er de ren dou you, suoyi na er de fangyan dou you...

Translation

\{traffic noise, people talk unintelligibly

1 X. *which ones* (of the steamed dumplings) would you like? \{weak slow voice, noticeably trying to pronounce in local Beijing accent

R. what kinds do you offer?

X. here we have...

$5 \quad \ldots$ \{conversations about the kinds of steamed dumplings he offers $\}$

R. you are doing a good business: so many people get their breakfast from you.

$\mathbf{X}$. $\{$ laughing voice $\} *$ only* good in the morning; no one comes in the afternoon \{ still making efforts at mimicking Beijing accent $\}$.

R. the morning business is good enough. Have you put the shrimp one in (the bag)?

$10 \mathbf{X}$. $\{$ nod with smile $\}$ that's a good one - we brought the shrimps from our hometown.

R. seriously?! Where is it?

X. \{proud, smile\} they are shrimps from the Yangtze river...good shrimps $\{$ his voice is noticeably higher and faster, and with clearer southern accent $\}$

... conversations about how they brought the shrimps from that far away place $\}$

15 R. you speak good Putonghua, did you learn that from school?

X. *just so-so*. Some (customers) couldn't figure out what I said fend with laughing voice, indicating this is a humble response

R. I found your Putonghua is really good, I have no problem understand you.

X. well, we learnt Putonghua in school. I studied up to high school \{ switches from

20 noticeable southern accent to near-Putonghua .

*are you* a Beijing person? \{smile, and switch to certain characteristics of Beijing accent $\}$

R. yeah, I am from here.

X. *from here* $\{$ repeat in a low voice, still in a effort of producing Beijing accent $\}$

25 R. did you all use Putonghua in school? 
X. we learnt (Putonghua in school) but also talk in our own dialect.

R. then how comes your Putonghua is so good \{smile $\}$ ?

X. I... I was here before $\{$ switch to his Beijing accent with a higher, prolonged and jolly voice, indicating he was pleased by my comment on his Putonghua, and was proud that

30 he was not a stranger to the city of Beijing

R. Do you (always) understand what people speak here in Beijing?

X. usually I can, when people talk in their dialects, I can't \{ switches back to Putonghua .

R. = sure. I can't if they use dialects.

$35 \mathbf{X} .=$ they use dialects when order steamed dumplings, for a few minutes I don't know what they are telling me $\{$ end with laughing voice, amused $\}$

R. that's right; also there is very mixed, you can find people from everywhere (of the country), and many dialects...

Let us take a close look at what happens in the transcript. The most noticeable thing here is the shifts of accents in Xiao Xu's discourse, and the shifts appear to be thematic and systematic. ${ }^{10}$ First, Xiao Xu greets his customer and attempts to talk with a Beijing accent in the beginning of the conversation from line 1 to line 11 - notice that he uses toneless

[mə] which is rare in southern dialects but common in Beijing accent. This can be seen as a technique of narrowing the gap between him and his customers, but at this stage, he doesn't know whether this customer is a local Beijing person or not. It would make more sense if he used Putonghua, the standardised Chinese based on the Beijing accent; he decides to greet his customers with an attempt at mimicking the local accent. Here he speaks in a space - an urban street in Beijing and presumably filled with local people. This space is peripheral in relation to central Beijing, but central in relation to his hometown. The space thus actively shapes his choice of linguistic forms - the accent he perceives as Beijing accent. Also notice that here (in contrast to other parts of the conversation) he uses a low and slow voice, probably signalling the effort he invests in producing this 'central' accent.

${ }^{10}$ A similar analysis on discourses can be found in Maryns and Blommaert (2001) and Blommaert (2005b). 
The second turn appears when Xiao Xu talks about the shrimps he brought from home in line 12. His voice is higher and faster in this part, along with the shift from his perceived Beijing accent to a more southern accent when the topic of the conversations drifts to his hometown, in which a lexical difference is most obvious: eat/taste is [ch'ri $\left.{ }^{1}\right]$ in Putonghua or Beijing accent but $\left[\mathrm{k}^{\prime} \mathrm{e}^{1}\right]$ in Xiao Xu's southern accent. This change of style echoes the observation in the first turn: low and slow voice in the perceived Beijing accent, whereas high and faster voice in his provincial accent. The shift of accents occurs simultaneously with the style change when the conversations travel across spaces: from Beijing to his hometown in southern China. The shift of accents introduces one more space into the conversations: a far away place where Xiao Xu came from. The spaces are ordered and organised through a scaling process: Beijing the centre and his hometown, a peripheral place in relation to Beijing; he conducts business in the centre, and uses some of the materials from the periphery.

The third shift occurs in a metapragmatic talk about Xiao Xu's Putonghua in line 19. In this part, I direct the conversation in the way that Xiao Xu has to talk about how he talks, and how he perceives others talk in this particular space. He reflects that his Putonghua is average, but his laughing voice indicates that he is rather proud of his repertoire and skills in Putonghua. He also points out in line 19 that he has a high school education background which may give him the access to prestige varieties of Chinese, a semiotic resource from which indexical meanings and values can be derived. As argued above, semiotic resources are layered and stratified; in Xiao Xu's hometown, high school education can be a high-scale resource, and access to such a resource enables his social mobility. Acquiring Putonghua from his education also facilitates his move across spaces: it is a linguistic resource that affords mobility. However, recall that resources in different spaces are not readily exchangeable, because spaces are positioned in relation to one another unequally, organised through scaling processes. Xiao Xu's movement across spaces is also a movement across scales of social structures. In this fragment of metapragmatic talk, Xiao Xu noticeably switches from a southern accent to near Putonghua, when the conversations change from the shrimps to how he perceives his talk. This accent shift is probably due to an attempt of proving his capability in Putonghua, which occurs simultaneously with the spatial change in the conversation. 
Xiao Xu raises a question immediately afterwards, and says: "*are you* a local Beijing person" in line 21 , reverting the question-answer pattern which is established during the conversations. Notice that "are you" is much weaker and quicker than the rest of the sentence, which is, in one sense quite close to Beijing accent by merging "are" into "you" so that the two syllables almost sound like one, but in another sense, making this question less threatening and more flattering by weakening "are you". It can be offensive and may trigger a conflict if "are you" is emphasised here, implying a challenge of the researcher's position in judging the migrant's linguistic ability. By weakening "are you" and merging "are" with "you", the utterance projects a positive and less challenging intention.

Xiao Xu's question is interesting in several senses; firstly, about space and scale: Putonghua is standardised based on the Mandarin spoken in Beijing and its nearby areas over a few hundred years; this projects the prestige status of Beijing accent linguistically as well as sociohistorically. It coincides with Beijing being one of the centres of the state, if not THE centre, in a polycentric and stratified system of symbolic spaces as well as spaces in reality. Therefore Beijing is a space of higher scale than where Xiao Xu comes from, and the Beijing accent, upon which Putonghua is standardised, marks this space as a non-neutral non-egalitarian place. The access of the rare resource, i.e. high school education, and hence the acquisition of the standard language variety buys Xiao Xu a ticket in the move across space and scales into Beijing.

More interestingly, Xiao Xu's question displays a performative process of identity construction on a language ideology level. As Blommaert and others point out that identities are achieved as well as ascribed, i.e. one's self-constructed and claimed identities (so called 'achieved' or 'inhabited' identities) have to be recognised by others - ascribed or attributed identities - so as to be established in social reality (Blommaert 2005a, 2006; Hinnenkamp 1991; also see Butler 1990 and Goffman 1981). Here the conversations prior to the question "are you a Beijing person” triggers the dialogical practice of establishing individual identities. Before Xiao Xu's question, the conversations are about his hometown, his Putonghua, and his education background. Jie, being a local person and thus representing the 'centre', assumes a role of judging Xiao Xu's accent, although in a friendly and flattering way, enacting the indexical meaning on wider and bigger sociolinguistic issues such as the place of origin, 
education level, and social categorisation. The question leads the conversations into an explicit social interaction in which identities are claimed and ratified in a performative and mutual process.

Xiao Xu's individual identity is not a singular and stable category but a repertoire of multiple identities that are organised unequally in relation to the access of the identity-building resources: it is a spectrum of possible categories that have been produced through access to the semiotic resources which construct identities and carry layered value. As the semiotic resources are stratified, so are the identities. Identity in one space may not be readily converted into its counterpart in another space. This is also applies within one country: one may be an important figure in his village, but becomes nobody in a big city. The access to high school education project prestige identity in Xiao Xu's hometown, but does not project a similar identity in Beijing, the central space in the centre - periphery model.

There are several layers of Xiao Xu's multi-identities displayed in the conversation: when he speaks about the shrimps from his hometown, he switches to a marked provincial accent which indexes his identity of coming from that particular place; this is performed in a othering process - him being of provincial and Jie being central. During his metapragmatic talk about his Putonghua, he shifts to a near-Putonghua accent which enacts his identity of high social mobility and hence an elite identity. But this identity is not stable: as mentioned above, identity does not travel easily across spaces, and therefore he is in a process of seeking ratification of his identity in a new and up-scale space.

In line 24 he repeats Jie's answer "from here" in a low voice, trying to reproduce the utterances in the same way that she does, with an $[\mathrm{r}]$ attached to "here" (zhe $+e r$ in Chinese) to make it a marked Beijing accent. This echoes his fourth shift of linguistic style in line 28 "I was here before". Here Xiao Xu switches from a low, weak voice in line 24 to a higher, prolonged and jolly voice, indicating a positive response to Jie's comments on his Putonghua, but also emphasising that he learnt Putonghua partly from the interactions with local people, that this is not his first spatial movement from his hometown, and therefore he is not one of 'others' when interact with a local person. Given the fact that he owns the business, he must have been in Beijing for a while, plus his earlier experiences of the city, he may have achieved a new local identity, or at least an identity of burgeoning entrepreneur in Beijing. This is 
confirmed in the later conversations between him and Jie about how he set up the business and what he plans to do in the future. This newly achieved identity needs to be recognised through a performative process such as this one in the central space.

The next part is a metapragmatic talk on how Xiao Xu perceives other provincial accents and dialects. He indicates that his Putonghua is usually enough to understand people who speak in Putonghua, but not those when they use their respective dialects. Simultaneously he switches back to near-Putonghua and put emphasis on 'their' in the utterances 'talk in their dialects', to imply that 'they' use dialects, 'I' or 'we' don't. This is again an othering process in which he categorise people who use dialect as 'others', whereas him and me as 'us'. Later in the conversation (not transcribed here) he speaks about this experience of working in Shanghai, one of the central spaces of the state similar to Beijing and another popular destination for migration in southern China, and comments that local Shanghai people of lower-class can not or are not willing to speak Putonghua, because of inadequate education or low awareness of the importance to speak Putonghua. His comments confirm the observations of the othering process when he describes that others talk in their dialects whereas he and $I$ use Putonghua. Here education is again a rare resource, so is Putonghua, and both project prestige identities.

In the fragment of the conversations between Xiao $\mathrm{Xu}$ and Jie, we observe complexes of linguistic patterns, i.e. accents and communicative styles, systematically deployed towards topics and interlocutors. Xiao Xu takes different positions according to the topics and the spaces of the interaction, and the shifts in positioning articulate different categories of identity. The positioning is what Goffman (1981:128) called 'footing', and the shift in footing projects a change in the alignment that one has to the others in the interaction. The way Xiao Xu organises his accents and the way he interacts with his local customers, reflect the centre-periphery model of spaces, from Liu Zhuang Street to central Beijing, from Beijing to Xiao Xu's hometown. And the spaces are ordered in the hierarchical social structure through scaling processes. What we see here is how Xiao Xu is polyglot in one language, and how this polyglot repertoire is organised indexically in relation to layered and stratified spaces. 


\section{Conclusion}

What we hope to have achieved in this paper is the application of scale and spatial analysis in empirical research on linguistic micro-variations in China, and the indexical order of linguistic forms in the construction of individual identities within the theoretical frame of language ideology. Space actively and systematically defines the patterns in which people communicate with one another, and the positions people take in orienting towards the topics and the interlocutors, and therefore construct their individual identities in the performative process through social and linguistic interactions. Spaces exist in relation to one another and are organised in a layered and stratified social system through scaling processes. The notion of scale emphasise the indexical nature of spaces that are ordered and organised in a vertical continuum, from local to translocal, to global. An upscaling move across spaces is often a move of power because such move entails access to semiotic resources that are subject to inequality.

The notions of space and scale shed new light on China's recent internal migration and the linguistic micro-variations. The migration wave has been going on at a large scale for about two decades, and the population movements across spaces result in increasingly intensive linguistic exchanges among various communities in China, a country that is enormously rich in linguistic and sociolinguistic diversity. The three vignettes presented in the paper illustrate a more nuanced sociolinguistic approach than the traditional ones, so as to address the real social impacts of language variation.

The first vignette demonstrated a monoglot ideology of language in which Putonghua emerged as a homogeneous image that overlies the linguistic diversity. The migrant child's linguistic repertoires are assessed against the local pupils' criteria and are disqualified as 'language-less'. The vignette points to a connection between the acquisition of Putonghua and better opportunities in life, which reflects the monoglot ideology of language: Putonghua is the language for public life and enables social mobility of those who speak it, whereas it functions as a barrier for those who do not speak it. This was also observed in the second vignette, in which the monoglot ideology disqualified the migrant worker's linguistic resources as peripheral, and the peripheral accent projected a peripheral identity - the migrant identity. The migrant worker is thus silenced by the misrecognition of her language 
competence, in a space that ranks her accent low through scaling processes. The monoglot ideology produces a collective or institutional habitus that makes some people's speech meaningless - the Sichuan child introducing herself to local pupils, and of the cleaner attempting to communicate with middle-class customers.

However, migrant workers are not always silenced by the collective habitus; they nevertheless navigate these obstacles by deploying the different codes and registers tactically in their social encounters. Such cases can be found in the third vignette that Xiao Xu displays complicated linguistic patterns involving characteristics of three language varieties: Beijing accent, near-Putonghua, and an accent of southern China. Xiao Xu gives an example of polyglot in one language, and this polyglot repertoire is indexically organised to project multilayered identities in relation in stratified spaces. Within a monoglot ideology, Xiao Xu moves across spaces and scales, organises his polyglot repertoire indexically, and takes different positions ('footing' in Goffman's term) in an attempt to avoid being misrecognised or silenced.

This research in exploratory; it deploys the notions of space, scale, monoglot ideology and polyglot repertoire in one language to analyse the complexity and micro-variation of the Chinese language in the context of mass internal migration and linguistic exchange, so that the fine-grained approach is able to address the real social effects of language varieties. Several areas of research need further in-depth enquiry. In particular, an analysis such as this one begs the question of historical trajectories leading to contemporary patterns: issues of standardisation, the trajectory of the language development and transfer over hundreds or even thousands of years, and the influence of the particular social and political history of China on sociolinguistic patterns. This, too, may require a conceptual apparatus that to many would seem experimental, but that may nevertheless be required to address both the general and the particular aspects of the case. 
References:

Blommaert, Jan 2005a. Discourse: A Critical Introduction. Cambridge University Press: Cambridge

Blommaert, Jan 2005b. In and Out of Class, Codes and Control. In Mike Baynham and Anna De Fina (eds.) Dislocations/Relocations: Narratives of Displacement: 127-143. Manchester: St Jerome.

Blommaert, Jan 2006. Sociolinguistic scales. Working Papers in Urban Language and Literacies 37.

Blommaert, Jan, James Collins and Stef Slembrouck 2005a. Spaces of multilingualism. Language and Communication 25:197-216.

Blommaert, Jan, James Collins and Stef Slembrouck 2005b. Polycentricity and interactional regimes in 'global neighborhoods'. Ethnography 6/2: 205-235.

Blommaert, Jan and Jef Verschueren (1998) Debating Diversity. London: Routledge.

Bourdieu, P. 1990. The Logic of Practice. Cambridge: Polity Press

Butler, Judith 1990. Gender Trouble: Feminism and the Subversion of Identity. New York: Routledge

Goffman, Erving 1981. Forms of Talk. Philadelphia: University of Pennsylvania Press

Chinadaily 2004. Greater numbers speak Mandarin. Online documents at http://www.chinadaily.com.cn/english/doc/2004-12/26/content_403419.htm last viewed on 7/12/2006

DeFina, Anna, Deborah Schiffrin and Michael Bamberg 2006. Introduction. In Discourse and Identity: 1-23. Cambridge: Cambridge University Press.

Fan, X.Z. (2004) Liudong ertong jiaoyu mianlin de zhengce wenti yu duice. Jiaoyu yu Jingji 4, 1-5. (On the financial problems facing the education of the floating children and some countermeasures. Education and Economics 4, 1-5.)

Goffman, Erving (1981) Forms of Talk. Philadelphia: University of Pennsylvania Press

Han, J.L. (2001) Beijing shi liudong ertong yiwu jiaoyu zhuangkuang diaocha baogao. Qingnian Yanjiu 8, 1-18. (Survey report on the state of compulsory education among migrant children in Beijing. Youth Research 8, 1-18.)

Hinnenkamp, Volker (1991) Talking a person into interethnic distinction: A discourse-analytic case study. In Jan Blommaert and Jef Verschueren (eds.) The Pragmatics of Intercultural and International Communication: 151-175. Amsterdam: John Benjamins.

Hymes, Dell (1996) Ethnography, Linguistics, Narrative Inequality: Towards an Understanding of Voice. London: Taylor and Francis.

Knight, J. and L. Song 1999. The Rural-Urban Divide: Economic Disparities and Interactions in China. Oxford and New: York Oxford University Press.

Kuijs, L. and Wang, T. (2005) China's pattern of Growth: moving to sustainability and reducing inequality. World Bank China Office Research Working Paper No.2 World Bank: Beijing 
Lu, S.Q. and Zhang, S.L. (2001) Chengxiang chabie xiade liudong ertong jiaoyu - guanyu Beijing dagong zidi xuexiao de diaocha. Zhanlue yu Guanli 4, 95-108. (Urban-rural disparity and migrant children's education. Strategy and Management 4, 95-108.)

Ma, X. (1999) New trends in population migration in China. In T. Scharping (ed.) Floating Population and Migration in China: the impact of economic reforms. P56-71 Hamburg: Institut für Asienkunde

Maryns, Katrijn and Jan Blommaert 2001. Stylistic and thematic shifting as a narrative resource: Assessing asylum seekers' repertoires. Multilingua 20/1: 61-84.

Ningbo Daily 2006. Putonghua rang wo rong ru zhege chengshi (Putonghua helps me integrate with this city. Online documents at http://www.cnnb.com.cn/gb/node2/newspaper/nbrb/2006/10/node69731/node69737/userobject7ai1326 148.html last viewed on 7/12/2006

Ramsey, Robert 1987. The Languages of China. Princeton University Press: New Jersey.

Scollon, Ron, and Wong Scollon, Susan 2003. Discourse in Place: Language in the Material World. Routledge: London

Silverstein, Michael 1996. Monoglot standard in America: Standardization and metaphors of linguistic hegemony. In D. Brenneis and R. Macaulay (eds) The Matrix of Language: 284-306. Boulder: Westview

Silverstein, Michael 1998. Contemporary transformations of local linguistic communities. Annual Review of Anthropology 27: 193-229

Silverstein, Michael 2004. Cultural concepts and the language-culture nexus. Current Anthropology 45/2: 175-214.

UNDP 2003. Millennium Development Goals China's Progress. United Nations Development. Programme: Beijing.

Wallerstein, I. 1983. Historical Capitalism. London: Verso.

Wallerstein, I. 2000. The Essential Wallerstein. New York: The New Press.

Wallerstein, I. 2001. Unthinking Social Science (2nd edition). Philadelphia: Temple University Press.

Wong, Andrew, and Qing Zhang (2000) The linguistic construction of the Tonghzhi community. Journal of Linguistic Anthropology 10/2: 248-278.

Woronov, T. E. 2004. In the eye of the chicken: hierarchy and marginality among Beijing's migrant schoolchildren. Ethnography. 5/3:289-313

Zhou, Minglang 2003. Multilingualism in China: The Politics of Writing Reforms for Minority Languages 1949-2002. Mouton de Gruyter: Berlin.

Zou, H., Qu, Z.Y. and Zhang, Q.L. (2005) Zhongguo jiu chengshi liudong ertong fazhan yu xuqiu diaocha. Qingnian Yanjiu 2, 1-7. (A survey on the development and needs of migrant children in nine cities in China. Youth Research 2, 1-7.) 